\title{
Engaging Families, Building Relationships: Strategies for Working Across Systems from a Social Exchange Perspective
}

\author{
Karen Rice \\ Heather Girvin
}

\begin{abstract}
In child welfare, the relationship between worker and client is viewed as the mechanism through which families may be engaged. Certain settings may complicate the development of a helping relationship and require workers to counter these pressures by developing more effective means of engaging families. Utilizing a social exchange framework, this qualitative study was conducted to explore interactions among parents and professionals in dependency court hearings. Findings revealed that a lack of reciprocity hinders the development of collaborative relationships that could support and assist families. Implications for social work practice are examined.
\end{abstract}

Keywords: Child welfare, engagement, helping relationship, social exchange theory, strengths-based perspective

The field of child welfare has moved toward the strengths-based perspective, with educators and practitioners emphasizing the importance of harnessing families' strengths (Alpert \& Britner, 2005). Engagement is foundational in this process and can be conceptualized as a way to protect the rights of children and families to exercise agency in case planning. In child welfare, the relationship between worker and client is viewed as the mechanism through which families may be engaged. Evidence suggests that the formation of a strong connection between the worker and client is prerequisite for effective intervention (Holland, 2000). Failure to establish a helping relationship has been associated with poor outcomes such as lack of reunification between the parent and child (Landsman, Groza, Tyler, \& Malone, 2001; Lee \& Ayon, 2004; Trotter, 2002).

Though viewed as vital to optimal practice (Dawson \& Berry, 2002; Gockel, Russell, \& Harris, 2008), engagement can be problematic in child welfare because of the involuntary context in which many services are delivered. Workers are often viewed by clients as adversaries, a perception related to the accurate assessment that workers wield power over interventions and case decisions (Sheafor \& Horejsi, 2009). Other stakeholders-families' attorneys, parents and caregivers, and guardians ad litem (attorneys appointed to represent the best interest of the child) - also maneuver within the context of child welfare with varying degrees of power and influence as well as pressure to achieve particular outcomes. When desired outcomes are at odds, as perceived or in actuality, the resultant conditions may create an environment in which family engagement is unlikely.

Decision-making time frames established by the Adoption and Safe Families Act (ASFA, 1997) have increased pressure on workers to use efficient practices, underscored

\footnotetext{
Karen Rice, Ph.D., LSW, ACSW, is an Assistant Professor and Department Chair and Heather Girvin, Ph.D., M.S.S., is an Assistant Professor both in the Department of Social Work at Millersville University in Millersville, PA. This study was partially supported through a grant from the Millersville University Faculty Grants committee. The authors would like to thank the public child welfare agency and dependency court for providing us access to key stakeholders to conduct their observations and focus groups.
}

Copyright (C) 2014 Advances in Social Work Vol. 15 No. 2 (Fall 2014), 306-317 
the need for collaboration among legal representatives, and raised expectations of parents, some of whom have only 12 months before a child's permanency goal could be changed from return home to adoption (Smith \& Donovan, 2003). Workers may be expected to counter these pressures by developing more effective means of engaging families; however, little is known about the everyday work and courtroom interactions of stakeholders in dependency court hearings (Smith \& Donovan, 2003). The study described here was prompted by evidence that the public child welfare system in one Mid-Atlantic county was not meeting desired outcomes (Children's Bureau, 2005), as well as anecdotal evidence that conflictual relationships among representatives of the various systems (workers, clients, attorneys, judges, guardians ad litem, youth) limited the degree to which stakeholders collaborated to meet children's needs. Throughout this manuscript, the term caseworker is used to reference frontline child welfare workers who often, but not always, possess a social work degree.

\section{Literature Review}

Child welfare agencies follow a bureaucratic organizational structure (Fabricant, 1985), characterized by a hierarchical ordering of individuals with well-defined roles and responsibilities (Gordon, 1970; Wasserman, 1971). Individual workers' attitudes, values, and behaviors within an organization are determined by its organizational climate (Gordon, 1970). According to Solomon (1976), public bureaucracies have the ability to adversely influence the employees, clients, and service delivery. As a result, it is essential to consider the factors that influence the development of a helping relationship within a bureaucratic organization.

\section{Contributing Factors to Engagement}

Social work is a profession grounded in social justice and the empowerment of others. Empowering families involved with child welfare may help keep children out of placement or may help reunify families (Hegar \& Hunzeker, 1988). However, Hegar and Hunzeker (1988) argued that certain characteristics of child welfare agencies and workers prohibit the development of a helping relationship. A number of qualitative research studies (e.g., Diorio, 1992; Drake, 1994; Kapp \& Propp, 2002; Maiter, Palmer, \& Manji, 2005; Ribner \& Knei-Paz, 2002) have documented specific caseworker skills, identified by both the client and the caseworker, as being associated with a helping relationship. Reoccurring themes in these studies include worker supportiveness, genuineness, empathy, helpfulness, respect, non-judgmental attitudes, accessibility, and use of effective communication skills. Winfield and Barlow (1998) assessed the strength of the helping alliance between the client and caseworker, finding that $95.6 \%$ of clients reporting a positive relationship viewed their caseworker as friendly.

A more recent study by Kapp and Vela (2004) also supported the need to develop a helping relationship. A sample of clients whose children were in foster care was surveyed to assess their perception of satisfaction with their caseworker. Clients reported higher levels of satisfaction if they believed the caseworker was helping them in reuniting with their child, had clear expectations, prepared them for meetings, stood up for them in meetings, and respected their culture (Kapp \& Vela, 2004). Chapman, Gibbons, Barth, 
McCrea, and NSCAW Research Group (2000) found that clients more often reported higher levels of satisfaction with their caseworker if they perceived the worker offered relevant and helpful services in a timely manner and if the caseworker maintained frequent verbal contact with the client. This would suggest that the client valued a worker who took the time to help the client accomplish his/her goals.

Yatchmenoff (2005) reminds us that organizational factors can influence clients' level of satisfaction, and thus the ability to develop a helping relationship. Findings revealed most clients' perceptions of the "system" were negative as they did not "believe my family will get the help we really need from" Child Protective Services (Yatchmenoff, 2005, p. 95). Therefore, more than ever, effective collaboration between the child welfare caseworker, family, and other service providers is an essential practice method to foster engagement and development of a helping relationship.

\section{Social Exchange Theory}

Social exchange theory (Blau, 1964; Homans, 1958) provides a lens through which human interactions and relationships can be examined. At the core of social exchange theory is the assumption that individuals seek to profit in their exchanges. Individuals are considered to be rational actors who consider costs and benefits before interacting with another. As individuals desire to achieve benefits and avoid costs, self-interest is a key motivating force. Homans (1958) argued that self-interest was a universal motive that made the world go around, and men and women modified their behavior in terms of positive or negative reinforcement provided by their environment (Coser, 1977).

Consequently, individuals will do what they perceive to be in their best interest and that which moves them closer to achieving what they define as valuable. Likewise, individuals will avoid actions that will cause them to lose what they value. Hence, individuals are seen as rational calculators of pleasures, always intent on maximizing returns and minimizing losses (Coser, 1977).

In an attempt to explain group conformity and deviance, Blau (1964) proclaimed that there is first an exchange transaction between individuals, which leads to a difference in status and power, which leads to legitimization and organization, which leads to opposition and change (Ritzer, 1992). Therefore, for groups to survive, each member must adhere to its predictable patterns of interaction within their ranks. Thus, the group norms and individuals' desire for social approval ensure conformity, which reinforces group cohesion and survival (Robbins, Chatterjee, \& Canda, 2006). When groups do not adhere to their predictable patterns, and there is an uneven exchange, then power of one person over another will prevail.

Ideally, norms of reciprocity triumph in an exchange. However, when one individual is not rewarded as expected, an imbalance is created, which threatens the operation of the social system. This leads to a differentiation in resources that individuals possess, creating a power base through which one becomes deprived or exploited (Coser, 1977). Individuals come to learn what is expected of them, and, in turn, this regulates their behavior. 
Social exchange theory allows for the explication of social, contextual, personal, and organizational factors that structure relationships among stakeholders in dependency court processes. The theory contains key theoretical concepts that allow observers of human behavior to consider how social interaction is related to participants' consideration of potential loss and gain, the impact of perceived rewards and their distribution, the role and function of power, the influence of norms, and reciprocity across exchanges (Robbins et al., 2006). Utilizing a social exchange framework, this qualitative study was conducted to explore interactions among parents and professionals in dependency court hearings with the objective of determining the degree to which families are engaged throughout judicial processes and actively involved in case decisions.

\section{Method}

\section{Research Design}

This exploratory study employed qualitative ethnographic strategies, using courtroom observations and focus groups with key stakeholders (judges, caseworkers, guardians ad litem, youth, and foster parents) to collect data. This approach was chosen to capture the complexity of social interactions among stakeholders from an emic perspective. Permission to conduct the study was granted by the university's Institutional Review Board as well as from the public child welfare agency's Executive Director and solicitor.

\section{Sample}

This study was based on focus group interviews and dependency court observations. Individuals observed during the dependency hearings comprised the judge, county solicitor, guardian ad-litem, parent's/caregiver's attorney, parents/caregivers, county caseworker, youth, and other professionals present in the courtroom (e.g., witnesses, sheriff).

Five separate focus groups were conducted with the following stakeholders: judges, guardians ad litem, county caseworkers, foster parents, and youth in foster care. The number of individuals within each focus group varied. Table 1 shows the composition of these groups.

Table 1. Composition of Focus Groups

\begin{tabular}{lrrr}
\hline Focus Group & Male & Female & Total \\
\hline Judges & 2 & 1 & 3 \\
Guardians ad litem & 3 & 3 & 6 \\
Caseworkers & 2 & 6 & 8 \\
Foster Parents & 1 & 4 & 5 \\
Youth & 7 & 7 & 14 \\
\hline
\end{tabular}


Except for the adolescent youth, who were selected by the county agency since they were a pre-existing group of youth in care who participated in the agency's Independent Living (IL) Program, all focus group participants were recruited to participate in the study. An email was sent to all judges, guardians ad litem, and county caseworkers inviting them to participate in the focus group. An invitation was sent to the foster parents through the agency's monthly newsletter. One hundred percent of the judges and guardians ad litem participated, $6 \%$ of the total number of foster parents participated, and $12 \%$ of the caseworkers participated. Although the youth were pre-determined and represented $100 \%$ of youth involved in the IL Program, they represented only $7 \%$ of the total population of youth in foster care 12 years old and older, the age range of youth who are invited to attend their dependency hearings. Having attended and/or testified in dependency court was the only inclusion criterion for the participants of the focus groups.

\section{Data Collection}

As a result of their professional relationship with the judge, the researchers gained access to the courtroom in order to obtain this emic perspective of the dynamics of dependency hearings. Although this relationship may have potentially biased the study's findings, the researchers used multiple methods of data collection and interpretation to enhance the trustworthiness of the results. These methods included prolonged engagement, peer debriefing, and multiple observations. Over a three-month period in 2009, the researchers observed six hours of dependency hearings. To ensure trustworthiness, two observers attended multiple court hearings presided over by the primary dependency judge and took field notes throughout. The observers sat in the back of the courtroom and only the judge knew why they were present. There was no verbal interaction between the observers and individuals being observed. The field notes from the court observations were typed and analyzed.

The focus groups were conducted by the authors, one acting as the primary facilitator. The focus groups were guided by a semi-structured interview guide that included open-ended questions on the participants' perceptions of the court process, the level of preparation for court, the ability to testify in court, and the relationships between key stakeholders in attendance. Each focus group lasted approximately 60 minutes and was conducted at a place of convenience for the participants (e.g., courthouse meeting room, local child welfare agency). The focus groups were audiotaped and transcribed.

\section{Data Analysis}

This study was purposefully designed so that data were triangulated, incorporating multiple viewpoints through focus groups and observations to avoid bias from any one group of stakeholders, including the researchers. Trustworthiness was enhanced through continuous and prolonged engagement of the participants and immediate documentation of insights and thoughts regarding the court proceedings (Padgett, 2008). Further, after initial coding of the field notes, emergent ideas were authenticated through peer debriefing, a common method of establishing trustworthiness (Padgett, 2008). Peer debriefing involved a review of the typed field notes and codes by a colleague with 
numerous years of experience in child welfare to assess for authenticity in interpretation of data.

Following the transcribing of focus group data, each transcript was reviewed line by line and coded by both authors using open coding techniques (Corbin \& Strauss, 2007). This first level coding utilized a constant comparison method of analysis (Corbin \& Strauss, 2007) in which this process was repeated several times to compare, clarify, and organize codes to ensure consistency and credibility of the data. Second level coding was performed to review and organize codes across all transcripts into common categories.

\section{Results}

Throughout the data analysis process, the theme of power, specifically power differences, quickly emerged. To elucidate this construct, the key concepts of social exchange theory became helpful in explaining and understanding the power differences. As a result, those key concepts (participants' consideration of potential loss and gain, the impact of perceived rewards and their distribution, the influence of norms, and reciprocity across exchanges) are used to structure the discussion of results.

\section{Potential Loss and Gain}

Within the context of dependency court, key decisions are made that can alter the life of those involved. It was evident after examining the data, those responsible for making those key life-altering decisions weighed the potential losses and gains and were often influenced by personal biases. For example, data from focus groups with the judges pointed to a child-centered approach that marginalized families of origin and reflected tension across collaborating agencies. One judge described the presumed biases in dependency hearings, "Birth parents complaining to high heaven that everything is just fixed." Through observations of dependency hearings, we noted that judges were critical of work done by "the Agency," but their negative perception of parents led them to trust a caseworker's testimony over that of parents.

Judges expressed an inability to understand the poor decisions and risky behaviors of biological family members. One judge stated, parents "shouldn't have had kids to begin with" and another stated, "we treat our dogs better." Supporting the notion that families involved with child welfare are "doomed," another judge stated, "they are already wrecked by the time the Agency gets involved." These sentiments clearly influence judges' decision-making process when weighing the potential losses and gains to keeping families together.

\section{Perceived Rewards and Their Distribution}

Key to this theoretical concept is that each group member adheres to a predictable pattern. As a result, they expect to be rewarded and anticipate that the rewards will be equally distributed across group members who adhere to those expected behaviors. Being part of the in-group affords one power, status, and alignment with the norms of the courtroom. Members of the in-group are more likely to be perceived favorably by the judge and hence have their views and opinions (i.e., recommendations) hold more weight 
in the decision-making process. As parents are not part of the in-group, the testimony they provide is not weighted equally.

It was immediately apparent during the observations of the dependency hearings that two types of "groups" existed, the "in-group" and the "out-group." Members of the outgroup were neither acknowledged nor engaged by members of the in-group. The in-group comprised the professionals, including the judges, attorneys, guardians ad litem, and caseworkers whose behavior reflected a disregard for the parents' role in decisionmaking/case planning. Negotiations among in-group members were observed being made before the hearing occurred. When it was time for the hearing, the professionals appeared to be "going through the motion," as decisions and plans were already made and/or based on hearsay/reputation rather than first-hand testimony and concrete evidence.

Data received from the focus group with the caseworkers supported the observations reported above. Caseworkers spoke at length about the unfair treatment received by "their families." "So many side conversations going on between the attorneys and lack of professionalism... while clients are in there...they (clients) don't feel that they are taken seriously." Another caseworker stated, "I feel like the parents are kind of standing there, like they're already hopeless 'cause, you know, they don't know what's going on and sometimes they feel like I don't feel like I can stand up for myself and it's like if their attorney's not even giving them the time of day, why should they feel any different than that."

This sentiment of unequal distribution was reiterated by the guardians ad litem who described an adversarial process that marginalized parents. "When you are in court, it is a very different atmosphere. It is very adversarial. Parents, they feel like they are being attacked. A lot of times the parents are blindsided so I understand the frustration level and why there is mistrust now with the Agency. Unfortunately that happens a quite bit."

\section{Influence of Norms}

The dependency court interactional norms and the physical layout of the area were exclusionary. Professionals were "at ease" while caregivers were "shuffled" in and out. There was a lack of instruction or direction provided about courtroom rules or expectations. In-group members moved comfortably across barriers to chat with the clerk and clustered for informal conversation near the judge's bench. Parents' space was restricted; family members remained standing and then were seated behind tables that were on the "right side" of the barriers that divide the judge from the courtroom audience. The professionals also used language that separated themselves from the parents and, at times, appeared to exclude parents from conversations thereby reinforcing professional solidarity. There was also an air of "nonchalance" that permeated the proceedings, rather than the sense of formality and respect that was expected given the serious nature of these cases.

Professionals' perceptions of parents, coupled with the parents' out-group status, minimizes parents' chances of being "rewarded" regardless of whether or not the parent adheres to the expected behaviors. In part, the physical space conveys normative expectations related to conduct within the courtroom and interaction among the various 
stakeholders. However, these expectations were modified or overlooked if the individual was a member of the in-group. For example, it was noted that attorneys for all involved parties were the "insiders" and did not have to follow rules of decorum that were applied to families such as cell phone use within the courtroom.

\section{Reciprocity Across Exchanges}

Most relationships among the professionals were reciprocal in nature; however the relationships between professionals and parents were not. Parents perceived less power in their exchanges with professionals. Among professionals, there was a sense of solidarity expressed through casual in-group conversation. Family members were not invited to participate. During focus groups, resource parents spoke at great lengths about judicial "power plays" and "the politics that nobody likes to admit," noting that families of origin were treated unfairly. "Every other person in the courtroom minus the biological parents has a working relationship with everybody else in the courtroom. All these people are on a first-name basis all the time."

Youth also reported a lack of reciprocity as well as relationships with professionals that were characterized by mistrust and unfamiliarity. "You are not really a part; you are just there as a visitor to the court." Another youth spoke to the lack of reciprocal exchange in the relationships between in- and out-group members. "They don't really say a lot of positive things in there; they point out mostly negative stuff." However, one youth had a different perspective, which reflects what occurs in reciprocal relationships. "When they see you are making an effort, they start to trust you and that really builds over time. You come 10\% and they'll come 10\%."

\section{Discussion and Implications}

Relationships between parents/caregivers and key child welfare stakeholders were examined in this study to identify the degree to which families are engaged throughout the dependency court process. Results illustrate that despite child welfare's focus on strengths-based, family-centered practice (Alpert \& Britner, 2005), a lack of reciprocity, supported by in-group/out-group dynamics, the culture of professionalism, and both actual and perceived courtroom norms and structure make it unlikely that collaborative relationships that support and assist families will develop.

Organizational conditions such as bureaucracy, large caseloads, legal and agency mandates, and both personal and professional biases create pressures against implementing best practices in the context of dependency court. Under pressure to keep children safe and move through hearings quickly, an "us versus them" mentality emerges that underscores the differences between professionals and the families of origin with whom they work.

The separatism of professionals and families is exacerbated by the cultural norms of dependency court, which begin to define the relationships between professionals and parents/caregivers. These courtroom norms (e.g., adversarial relationships, sterile environment) are contrary to social work's strengths-based perspective that promotes 
collaboration and reciprocity (Holland, 2000). Therefore, parents/caregivers may learn to expect little from the relationship with their caseworkers. This learned expectation may limit the likelihood of their follow-through on their service plans as they do not anticipate the reward of being reunified with their child. Social exchange theory would suggest that parents/caregivers might expect work required by their service plans to be fruitless, as the system appears biased toward professionals. Put differently, Agency and judicial demands and norms produce two groups - families and professionals - that are most distinguishable by differential access to power and markedly different expectations of rewards.

\section{Limitations}

The primary limitation of this study is that parents/caregivers were not interviewed; therefore, the findings may not adequately reflect their perspective. The study's results may only be representative of a particular place (one courtroom) and the time when the data were collected. Further, while social exchange theory provides a useful analytic lens, further observation and interviews are required to explore stakeholders' awareness of observed dynamics as well as their views on motivation. Despite these limitations, this exploratory study contributes to the limited knowledge of child welfare practice within the context of dependency court. The findings highlight some challenges that may be associated with translating best practices into everyday practice.

\section{Implications for Social Work Practice}

Though child welfare practice has moved toward intervention strategies that are strengths-based and centered on family engagement and worker-family collaboration, courtroom culture and systemic requirements have impeded the application of this approach to legal procedures and hearings. Further research may help to illuminate barriers and point to training and education that would address them.

Social exchange theory suggests that there are rewards for adhering to group norms. Rewards for the in-group (professionals) include professional validation, camaraderie, and the expediency of hearings. The degree to which members of this group are aware of this dynamic and/or pursue rewards strategically bears further investigation.

Cross-system training that engages social workers (i.e., caseworkers), attorneys, and judges in conversations about the reality of system pressures (e.g., caseloads, federal and state laws, and timelines) and the family-centered approach of child welfare practice may prove useful. The recognition that the cultures of court and child welfare may function at odds, though they are in pursuit of the same goal (child safety and well being), would be a fruitful starting point for ongoing dialogue and training across systems. A key goal of this training would be the teaching of strategies that build and/or strengthen qualities of a positive helping relationship between the professionals and parents/caregivers as well as providing tools that enhance advocacy skills. Tools that strengthen advocacy skills assist professionals in learning how to navigate what may appear to be contradictory goals, protecting children and maintaining families, in a way that enhances rather than hindering the helping relationship. As previously stated in the literature, fostering a positive helping 
relationship is key to any successful outcome in social work, including child welfare. Therefore, training that highlights power imbalances and ways to combat or manage them to foster a helping relationship and bring about positive change is essential in child welfare practice.

\section{Conclusion}

An improved understanding of the social structure of dependency court may inform child welfare practice and policy to enhance family engagement throughout judicial processes. Data may point to organizational, social, and/or personal factors that frustrate the attempts of workers to engage families and, more generally, impede the efforts of all involved parties to work collaboratively toward the goals of permanency and child wellbeing. Better understanding the challenges faced by professionals and parents/caregivers involved in dependency court may inform training that builds and enhances skills that can foster a supportive, helping environment.

\section{References}

Adoption and Safe Families Act (ASFA) of 1997, Pub. L. No. 105-89, codified at 111 Stat. 2115 (1997).

Alpert, L. T., \& Britner, P. A. (2005). Social workers' attitudes toward parents of children in child protective services: Evaluation of a family-focused casework training program. Journal of Family in Social Work, 9, 33-64. doi:10.1300/J039v09n01_03

Blau, P. (1964). Exchange and power in social life. New York, NY: John Wiley \& Sons, Inc.

Chapman, M. V., Gibbons, C. B., Barth, R. P., McCrea, J. S., \& NSCAW Research Group. (2000). Parental views of in-home services: What predicts satisfaction with child welfare workers? Child Welfare League of America, 82(5), 571-596.

Children's Bureau. (2005). Child and Family Services Reviews PIP Reports, Pennsylvania. Retrieved from http://www.acf.hhs.gov/programs/cb/index.htm

Corbin, J., \& Strauss, A. (2007). Basics of qualitative research: Techniques and procedures for developing grounded theory $\left(3^{\text {rd }} \mathrm{ed}\right.$.). Thousand Oaks, CA: Sage.

Coser, L. A. (1977). Masters of sociological thought: Ideas in historical and social context ( $2^{\text {nd }}$ ed.). New York, NY: Harcourt Brace Jovanovich, Inc.

Dawson, K., \& Berry, M. (2002). Engaging families in child welfare services: An evidence-based approach to best practice. Child Welfare, 81, 293-317.

Diorio, W. D. (1992). Parental perceptions of the authority of public child welfare caseworkers. Families in Society: The Journal of Contemporary Human Services, 73(4), 222-235.

Drake, B. (1994). Relationship competencies in child welfare services. Social Work, 39(5), 595-602. 
Fabricant, M. (1985). The industrialization of social work practice. Social Work, 30(5), 389-395.

Gockel, A., Russell, M., \& Harris, B. (2008). Recreating family: Parents identify workerclient relationships as paramount in family preservation programs. Child Welfare, 87, 91-113.

Gordon, L. V. (1970). Measurement of bureaucratic orientation. Personnel Psychology, 23, $1-11$.

Hegar, R. L., \& Hunzeker, J. M. (1988). Moving toward empowerment-based practice in public child welfare. Social Work, 33(6), 499-502.

Holland, S. (2000). The assessment relationship: Interactions between social workers and parents in child protection assessments. British Journal of Social Work, 30, 149-163. Retrieved from http://bjsw.oxfordjournals.org/archive/

Homans, G. C. (1958). Social behavior as exchange. The American Journal of Sociology, 63, 597-606.

Kapp, S. A., \& Propp, J. (2002). Client satisfaction methods: Input from parents with children in foster care. Child and Adolescent Social Work Journal, 19(3), 227-245.

Kapp, S. A., \& Vela, R. H. (2004). The unheard client: Assessing the satisfaction of parents of children in foster care. Child and Family Social Work, 9, 197-206.

Landsman, M. J., Groza, V., Tyler, M., \& Malone, K. (2001). Outcomes of familycentered residential treatment. Child Welfare, 80(3), 351-379.

Lee, C. D., \& Ayon, C. (2004). Is the client-worker relationship associated with better outcomes in mandated child abuse cases? Research on Social Work Practice, 14(5), 351-357. doi:10.1177/1049731504265833

Maiter, S., Palmer, S., \& Manji, S. (2005). Strengthening social worker-client relationships in child protective services. Qualitative Social Work, 5(2), 167-186.

Padgett, D. (2008). Qualitative methods in social work research ( $2^{\text {nd }}$ ed.). Thousand Oaks, CA: Sage Publications.

Ribner, D. S., \& Knei-Paz, C. (2002). Client's view of a successful helping relationship. Social Work, 47(4), 379-387.

Ritzer, G. (1992). Contemporary sociological theory ( $3^{\text {rd }}$ ed.). New York, NY: McGrawHill, Inc.

Robbins, S. P., Chatterjee, P., \& Canda, E. R. (2006). Contemporary human behavior theory: A critical perspective for social work ( $2^{\text {nd }}$ ed.). New York, NY: Pearson.

Sheafor, B. W., \& Horejsi, C. R. (2009). Techniques and guidelines for social work practice $\left(8^{\text {th }}\right.$ ed.). Boston, MA: Allyn \& Bacon. 
Smith, B. D., \& Donovan, S. E. F. (2003). Child welfare practice in organizational and institutional context. Social Service Review, 4, 541-563. doi:0037-7961/2003/77040003

Solomon, B. (1976). Black empowerment: Social work in oppressed communities. New York, NY: Columbia University Press.

Trotter, C. (2002). Worker skill and client outcome in child protection. Child Abuse Review, 2, 38-50. doi:10.1002/car.719

Wasserman, H. (1971). The professional social worker in a bureaucracy. Social Work, 16(1), 89-95.

Winfield, H. R., \& Barlow, J. A. (1998). Client and worker satisfaction in a child protection agency. Child Abuse \& Neglect, 19(8), 897-905.

Yatchmenoff, D. K. (2005). Measuring client engagement from the client's perspective in nonvoluntary child protective services. Research on Social Work Practice, 15(2), 8496.

\section{Author note}

Address correspondence to: Karen Rice, PhD, LSW, ACSW, Assistant Professor/

Department Chair, Social Work Department, Millersville University, PO Box 1002, Millersville, PA 17551. Email: karen.rice@millersville.edu 